\title{
Yasser's Maneuver for Regaining the Consciousness in the Psychogenic Coma; A Novel Maneuver in Emergency Medicine and Psychiatry
}

Yasser Mohammed Hassanain Elsayed

Critical Care Unit, Kafr El-Bateekh Central Hospital, Damietta Health Affairs, Egyptian Ministry of Health (MOH), Damietta, Egypt.

*Corresponding Author: Yasser Mohammed Hassanain Elsayed, Critical Care Unit, Kafr El-Bateekh Central Hospital, Damietta Health Affairs, Egyptian Ministry of Health (MOH), Damietta, Egypt.

Received Date: 10 September 2021 | Accepted Date: 12 October 2021 | Published Date: 19 October 2021

Citation: Y M H Elsayed. (2021). Yasser's Maneuver for Regaining the Consciousness in the Psychogenic Coma; A Novel Maneuver in Emergency Medicine and Psychiatry. Journal of Clinical and Laboratory Research. 3(5); DOI:10.31579/2768-0487/048

Copyright: (c) 2021 Yasser Mohammed Hassanain Elsayed. This is an open-access article distributed under the terms of the Creative Commons Attribution License, which permits unrestricted use, distribution, and reproduction in any medium, provided the original author and source are credited.

\begin{abstract}
Introduction: Psychogenic coma, generally is one of the most anxious and irritant problems in clinical medicine for all medical practitioners. Using recurrent painful or mischievous stimuli is contraindicated in a psychogenic coma.

Method of study and patients: My study was technical, prospective, observational, and interventional for 321 cases. The study was conducted in a physician outpatient clinic, Fraskour Central Hospital, and Ras-Al-bar Central Hospital. The author reported the 321 cases of psychogenic coma over nearly 5 years and 7-months, started from August 07, 2015, and, ended on March 07, 2021. Three selective groups were included in the study. Three groups were selected and evaluated for safety or complications and efficacy or responses.
\end{abstract}

Suggesting hypothesis: Yasser's maneuver can regaining the consciousness in a psychogenic coma.

The research objectives to evaluate this hypothesis might include: What is psychogenic coma? What is Yasser's maneuver? How can Yasser's maneuver do improvement of psychogenic coma? Is the study supported by past publicized literature studies?

Results: The range of age in the study was $16-55$ years with an insignificant $P$-value $(0.231)$. There is a female sex predominance for all groups (67\%). The response for the group I was: $(97.35 \%)$ ) vs. (85.85\%)) in group II, and (81.37\%) in group III. The most common associated risk factor was psychogenic hyperventilation syndrome (HVS); in the group, I was $79.6 \%$, in group II was $78.4 \%$, and in group III was $96.2 \pm 1.7$ with no statistical significance ( $P$-value 0.74$)$.

Conclusions: The author concluded that Yasser's maneuver is easy, available, quick, non-costive, time-saving, and extremely safe in the psychogenic coma. Very few and mild few mild complications for this maneuver encourage the generalizing use in the psychogenic coma.

Keywords: yasser's maneuver; regaining the consciousness; psychogenic coma; hysterical coma; coma; loss of consciousness

\section{Abbreviations}

ED: Emergency department

EEG: Electroencephalography

$\mathrm{CO}_{2}$; Carbon dioxide

GCS: Glasgow Coma Scale

IHD: Ischemic heart disease

$\mathrm{O}_{2}$ : Oxygen
PaCO2; Partial pressure of carbon dioxide

PO2: Partial pressure of oxygen

\section{Introduction}

\section{Psychogenic coma}

Introduction, definition, and prevalence 
A loss of consciousness is one of the most anxious clinical medical presentations [1]. The psychiatric disease can similar to a comatose patient [2]. Psychogenic coma is a commonly considered cause in the differential diagnosis of coma ${ }^{1}$. Hysterical coma, feigned coma, dissociative amnesia, dissociative stupor, factitious unconsciousness, and conversion coma are alternative synonyms for psychogenic coma [1]. Psychogenic coma is defined as a manifestation of a psychiatric illness that presents as a state of unresponsiveness without organic cause [1]. Psychogenic coma is a status in which the patient has keep level of consciousness and awareness, but does not communicate with the environment and does not display the external manifestations of consciousness [3]. Functional coma is defined as an involuntary comalike state that occurs in the absence of structural or metabolic damage to the brain and that is distinct from catatonia [2]. This term should supplant the previous phrase of "psychogenic coma" [2]. Functional coma is a prolonged motionless dissociative attack with absent or reduced response to external stimuli is a relatively rare presentation [4]. Depending on DSM-IV-TR guidelines, psychogenic coma is a dissociative illness not otherwise specified [5]. Time is the decisive factor to avoid catastrophe ${ }^{1}$. A wide range of terms is used to describe states of unresponsiveness in which psychologic factors are relevant to etiology, such as depressive stupor, catatonia, nonepileptic "pseudo-status," and factitious disorders, and discuss the place of functional or psychogenic coma among these [4]. Unfortunately, little information about this condition in the medical literature is mostly due to contradictory terminologies and by a deficiency of strong based-evidence [2].

Psychogenic coma is commonly mentioned in textbooks as a possible cause for coma. But, unfortunately, it is often ranked at the bottom of the differential lists with a small incidence rather than neglect its percentages [6]. For example; in a review of 405 patients with psychogenic dysfunction, there was only one case among all those patients who had a psychogenic coma [7] and approximately, 50\% of those patients, preoperatively, had happened [2].

\section{Etiology}

Despite the causes of psychogenic coma are numerous but currently, the precise etiology is still unknown [1]. Where no underlying medical condition is found [5]. Psychiatric disorders are frequently premorbid estimates but are not required for the diagnosis [2]. Delayed awakening after general anesthesia due to psychogenic coma is a phenomenon that rarely presents to the oral and maxillofacial surgeon. Psychogenic coma may be a complication of general anesthesia in dental extractions. It is recommended that patients at risk of conversion disorder should be counseled about the risks of psychogenic coma [8].

\section{Psychogenic comas; differential diagnosis}

Cases of the locked-in syndrome may be present with the voluntary movement of their eyes [5]. While those of psychogenic comas evince active resistance for the passive opening of the eyelids with abruptly and completely closed eyelids [5]. Life-threatening causes of coma should be instantly excluded especially the unresponsive patient with inconsistent physical examination [1]. Functional coma should be differentiated as a discrete entity from catatonia and psychogenic non-epileptic seizures [2]. A conversion reaction resulting in a functional coma is the most common unique diagnostic challenge [2].

\section{Symptoms and Signs}

The patients of psychogenic coma are clinically present as asleep, unrousable, and unresponsive [9]. In this coma, the eyelids are kept cruelly closed and are resistant to opening. Oculocephalic responses are unforeseeable for nystagmus is apparent after caloric testing. The motor tone is normal or discordant and limb reflexes are conserved. Other clinical findings depending on self-protective reflex have been tried in this syndrome despite their legality has not been officially estimated. The presence of firm resistance to eye-opening is reasonably evidenced as a sensitive and specific technique for functional coma, also the eye gaze sign, in which patients tend to look to the ground when turned on to one side [4]. Clinical examination can supply useful keys, especially, passive resistance to eye-opening or avoidance of the face with arm drop [2]. Psychogenic coma can be lasting for several hours or even several days in the absence of an underlying organic disease [10].

\section{Diagnosis and workup}

Traditionally, diagnosis of the functional coma has often been attained after extensive workup and exclusion of other probable diagnoses [4]. Prompt diagnosis of psychogenic coma could lead to better management [8], reducing morbidity and/or mortality, and hospital cost [1]. Psychogenic coma is a diagnosis of exclusion [5]. Early diagnosis of this condition would be reducing iatrogenic complications, hospital cost, and anxiety [1]. Hand drop test of attentiveness, when the physician directly held the patient's hand to be above his/her head in the supine position then left dropped, the hand would avoid hitting her face or the hand tends to fall to the side in psychogenic coma $[1,11]$. There is active resistance to passive opening of the eyelids with a tendency for abrupt closure of eyelids and completely when the lifted upper eyelid is test-off [11]. Strictly closed eyelids that resist attempts to open and eyelids that quickly snap shut after opening is reliably indicating psychogenic origin [12, 13]. This response is slowly, asymmetrically, and incompletely in an organic coma [11]. Whereas, in a coma due to general medical disorders or toxins, the hand tends to fall on the face [11]. Interestingly, there is some argument over the authenticity of this test [11]. The drama of psychogenic coma is a clinical history where the alteration in degree of consciousness after stress and the patient suddenly drops to the floor without hitting his head that strong guide keys [6]. The present observer at the scene often helpful for decisive description. All eye findings that will be seen on physical examination should be recorded $[6,14,15]$. The gently stroking of eyelashes may be inducing fluttering of eyelids. Spontaneous eye movements are usually fleetly and trembled rather than slowly roaming 11]. An active resistance on physical examining of tone or cogwheeling resistance with sudden"giving-away" phenomena may be present [11]. Bell's phenomenon with rolled back of eyes and commonly unilateral deviation away from the examiner or down also was prescribed in the patients of psychogenic coma [11].

The patient may occasionally make voluntary movements or change body position in bed [11].

Supplementary workup laboratory tests such as brain imaging, and electroencephalography (EEG), may be obtained. But, unfortunately, these tests unremarkable in psychogenic coma ${ }^{2}$ An electroencephalogram test detects awake rhythms [16].

\section{Survival}

Weiss, N. et al. study (2012) [17] assessed the etiologies of coma and their up-growth in the critical care unit for 4,482 patients; they revealed that there was admitted psychogenic coma were; 7 (0.3\%), mean GCS at hospitalization was; $6 \pm 3$, and the survival rate was; 7 (100\%).

\section{Management}

Management of psychogenic coma is generally supportive. Reassuring and avoiding repeated painful stimuli are the principle. Family education for other professionals on the real symptoms and non-consciously feigned presentation is noteworthy. Short-acting anxiolytic and/or antipsychotic drugs may help regain consciousness ${ }^{5}$. The role of the psychiatrist is concordant and outstanding [5]. Just the diagnosis of the psychogenic coma has been established, no more treatment is advised over supportive measures [1]. Psychiatrists mostly manage these patients with altered 
levels of consciousness in the emergency department (ED) and internal medical wards [5].

\section{Use of repeated painful or noxious stimuli}

Using recurrent painful or mischievous stimuli is contraindicated in psychogenic coma $[11,18]$. There may be intense psychological grief crushing the patient. So, it is important to still sensitive factor in helping the patient to kindly consciousness recovery [5]. Subsequently, using recurrent painful stimuli is strongly not advisable [4]. Harvey's sign as one of the noxious stimuli that can be processed by application of a highfrequency vibrating tuning fork on the nasal mucosa may be helpful. The result of using sternal or nail bed pressure in patients with psychogenic coma was often highly unresponsive to this painful stimuli [4]. In one case-study, clinicians were so insistent and persistent trials to compel the patient to awaken they went as far as occluding his airway for 60 seconds after "vigorous" painful stimuli were unsuccessful in eliciting a response [5]. Physicians may think that the patient of the psychogenic coma has conscious control over these psychiatric symptoms engaging in a battle to outmaneuver trying to triumph against the patient [5].

\section{Neural Control of Breathing and $\mathrm{CO} 2$ Homeostasis}

\section{Neural mechanisms are implicated in matching the metabolic production of $\mathrm{CO} 2$}

The chemoreflex, central control, and neural feedback from muscles are embroiled the three categories of neural mechanisms in the metabolic output of carbon dioxide $\left(\mathrm{CO}_{2}\right)$ and expulsion by the lungs [19]. The central respiratory chemoreflex is the breathing driving triggered by higher brain $\mathrm{PaCO}_{2}$ (central hypercapnia). But, the peripheral chemoreflex is the breathing driving triggered by activation of the carotid bodies and aortic bodies [20,21]. The carotid bodies are stimulated by arterial hypoxemia (reduced $\mathrm{PaO}_{2}$ ) in a $\mathrm{pH}$-dependent pattern, lack of blood flow, increasing of blood lactate, potassium, and catecholamine [21]. The chemoreflex decreases $\mathrm{PaCO}_{2}$ variations by inducing respiratory correction changes in ventilation and $\mathrm{CO}_{2}$ disposal. This process runs constantly due to tonic stimulation of respiration by chemoreceptors [20, 22]. The chemoreflex is state-dependent and, reciprocally, chemoreceptor stimulation produces arousal. The neural mechanisms that underlie these reciprocal interactions are important in sleep-related pathologies [23]. The cellular sensors and molecular detectors dependent-central respiratory chemosensitivity and the neuronal communication that will stimulate breathing and arousal [24, 25, 26].

\section{Brain PO2 and controls breathing}

During standard physiological situations, both blood and brain PO2 and $\mathrm{PaCO} 2$ are kept at steady concentrations by central controlling of breathing activity. The central respiratory drive is more sensitive to arterial $\mathrm{PaCO} 2$ changes. Even there are slight elevations in arterial $\mathrm{PaCO} 2$ it will quickly trigger a rise in minute ventilation. $\mathrm{CO} 2$ concentrations are controlled by the peripheral chemoreceptors of the carotid bodies, chemoreceptors of the aortic bodies, and central chemoreceptors of the Medulla Oblongata (MO) [27].

\section{Carbon dioxide and its effects on the brain}

The likely effect of $\mathrm{CO}_{2}$ inspiration on central performance is still not known [28]. Nevertheless, $\mathrm{CO}_{2}$ is recognized to have a vigorous vascular effect that is present even in absent neural activity [29]. Carbon dioxide is a strong vasodilator with increasing $\mathrm{CO}_{2}$ in the inspired air. This is causing several vascular changes in the brain such as increased cerebral blood flow, cerebral blood volume, and higher oxygen $\left(\mathrm{O}_{2}\right)$ blood levels [28]. The CO2-mediated change of brain extracellular $\mathrm{pH}$ is the elementary step resulting in changes in vascular tone. Adult cerebral circulation responds to $\mathrm{CO}_{2}$ via prostanoids that are important in regulating cerebral circulation. The effect of $\mathrm{pH}$ on cerebral vascular tone is mediated by nitric oxide (NO), prostanoids, cyclic nucleotides, potassium channels, and intracellular calcium. Most data available support an important role for each of these mediators in the response of the cerebral circulation to $\mathrm{CO} 2[30]$. An increase of $\mathrm{CO}_{2}$ normally triggers a reflex that increases cardiac output, augment breathing with access to $\mathrm{O}_{2}$, arousal, and turning the head during sleep [31].

\section{Method of study and patients}

My study was technical, prospective, and interventional for 321 cases. The study was conducted in the physician outpatient clinic, Fraskour Central Hospital, and Ras-Al-bar Central Hospital. The author reported the 321 cases of psychogenic coma over nearly 5 years and 7-months, started from August 07, 2015, and, ended on March 07, 2021 (Table 1) The patients in the study were classified according to the used method for recovery or regaining the consciousness into three groups. Group I was undergone to Yasser's maneuver. Group II was undergone for nontraditional methods. Group III observationally was left for spontaneous recovery. All three groups were evaluated for safety or complications and efficacy or responses were reported (Table 2).

\section{- Suggesting hypothesis and research objectives}

- Suggesting hypothesis: Yasser's maneuver can improve the psychogenic coma.

- The research objectives to evaluate this hypothesis might include: What is psychogenic coma? What is Yasser's maneuver? How can Yasser's maneuver do improvement of psychogenic coma? Is the study supported by past publicized literature studies? Is there a relationship between Yasser's maneuver and the improvement of psychogenic coma? What is the magnitude of both psychogenic coma response and complications of Yasser's maneuver in the study?

\section{- The cases were divided into three groups:}

Group I: It included 113 patients (35.2\%) of psychogenic coma. These cases were treated with Yasser's maneuver using the seconds as a unit for recovery of the consciousness. The duration of each time ranged from minimally 5 seconds to maximally 15 seconds (duration for each maneuver/ sec). The maximal trials of maneuver (times frequency) up to 5 times.

Group II: It included 102 patients (31.78\%) of psychogenic coma. These cases were treated using non-traditional methods (e.g., painful stimuli). The duration of each time ranged from minimally 2 minutes to maximally 20 minutes (duration for each maneuver/ minutes). The maximal trials of maneuver (times frequency) up to 10 times.

Group III (control): It included 106 patients (33.02\%) of psychogenic coma. These cases observationally were left for spontaneous recovery. The duration of recovery of the consciousness is determined by hours (Table 3).

- All cases in the three groups were undergone a complete physical examination, vital signs assessment, GCS scaling, \% of $\mathrm{O} 2$ saturation measurement before and after recovery of consciousness.

- Both safety or complications and efficacy or responses in all groups were reported. For more details see the summary of the study data (Table 2).

- Assessment of treatment response was done with the presence of either:

- Entirely (positive response) recovery of the consciousness.

- Or absent of recovery of the consciousness (negative response).

- All the above criteria were assessed in parallel to the clinical status. 
- No randomization was used in the assignment of patients for the three groups with the presence of psychogenic coma. All cases were selected.

\section{- Selection criteria}

1. The author think that the sample that was taken for psychogenic coma was representing the population of interest.

2. Researcher uniformly applied inclusion/exclusion criteria to all comparison groups as in text. Strongly excluding the alternative differential diagnosis for psychogenic coma was considered. The selection of the comparison group was appropriate.

3. An important outcome was assessed and reported, and Is my maneuver predominately will be effective in the recovery of psychogenic coma?

4. The length of follow-up was short but appropriate for the psychogenic coma.

5. There is no differential loss to follow-up for cases of psychogenic coma were reported to be considered in the analysis.

\begin{tabular}{|l|l|}
\hline Issue & Definition \\
\hline Title & $\begin{array}{l}\text { Yasser's maneuver for regaining the consciousness in the } \\
\text { psychogenic coma; a novel maneuver in emergency medicine } \\
\text { and psychiatry }\end{array}$ \\
\hline Estimated enrollment & 321 participants \\
\hline Study type & Technical, observational, and interventional \\
\hline Observational model & Case-control \\
\hline Time & Prospective \\
\hline Study date & August 07,2015, and, ended on August 07,2021 \\
\hline
\end{tabular}

Table 1: Showing remarks of the study method and data.

\section{- Eligibility criteria:}

- Inclusion criteria: All cases of psychogenic coma.

\section{- Exclusion criteria:}

1. Evidence of respiratory failure or central cyanosis, asthmatic or wheezy chest.

2. Patient of known IHD or suspected ischemic chest pain.

3. Suspected acute pulmonary embolism.

4. Suspected stroke.

- A diagnostic conclusion that the patients were suffering from "psychogenic coma was mainly based on a rapid exclusion for the serious organic causes of coma. This immediately ruling out cardiovascular/respiratory and other metabolic causes of coma. Quick history taking from relatives or friends, the immediate rapid clinical exam for ruling out stroke, hypertensive crises, uremic coma, hepatic coma, diabetic coma. Considering clinical signs of psychogenic coma as in the text literature in parallel with history was strongly taken. Rapid testing like random blood sugar nearly for all cases. Brain CT scan for doubt sporadic selected cases. ECG also was done for selected cases of suspected acute pulmonary embolism or myocardial infarction.

\section{- Statistical Analysis}

ANOVA test was used for statistical analysis in the triple numerical data. Number, percentage, mean, standard deviation, and median were used in the presentation of descriptive data. Results were considered significant at $\mathrm{p}<0.05$.
6. Clinical assessment for the outcome and predictor of the study cases of psychogenic coma was done in the same way for every presented patient with psychogenic coma. Post-maneuver assessment was applied.

7. The author think that the used statistical methods and study design in this study were adequate for minimizing confounding with psychogenic coma.

8. The Yasser's maneuver intervention was clearly described and can be transferrable for someone else to repeat this study with different staff and patients and get similar results.

- Psychiatric care or receiving medication management at the time of becoming comatose. Otherwise very few cases, oral benzodiazepines may be added with a low dose for short time. Advice is given to relatives if the coma would be recurrent, you should consult a psychiatrist.

- The patient's informed consent was taken. Ethical issues were considered. The data in this study did not include personal information or the identity of the patients. 


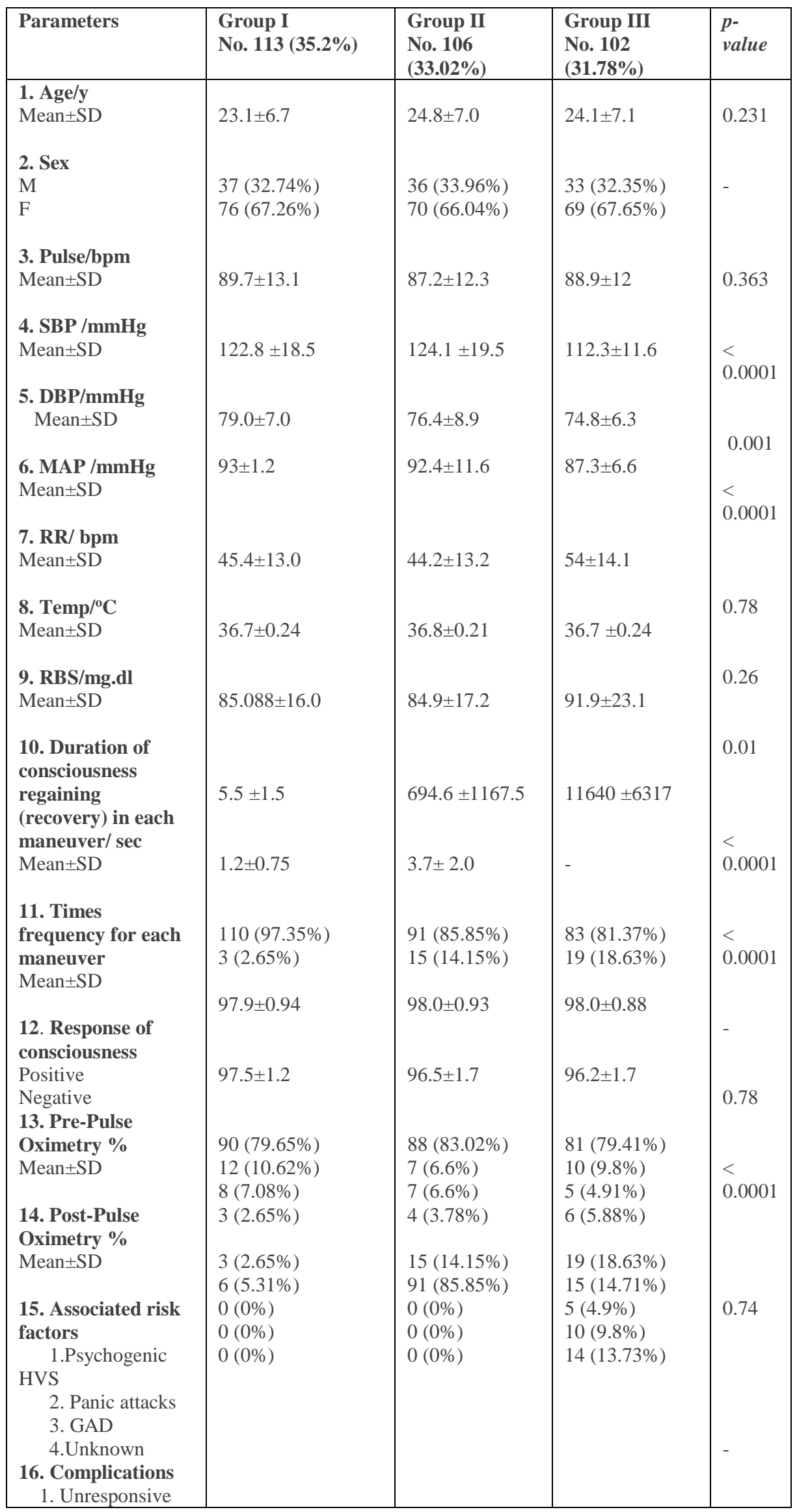




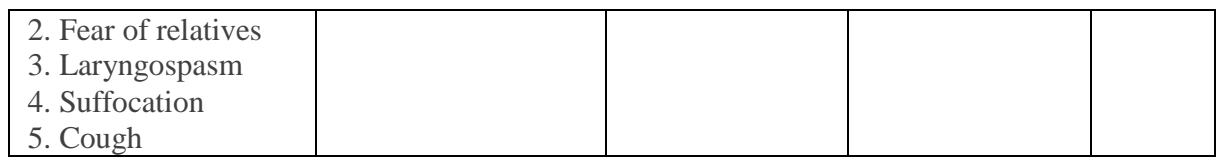

Table 2: Summary of data in all groups

Abbreviations: DBP; diastolic blood pressure, F; female, GAD; generalized anxiety disorder, HVS; hyperventilation syndrome, M; male, MAP; mean arterial pressure, RBS; random blood sugar RR; respiratory rate, SBP; systolic blood pressure Tem; temperature

\begin{tabular}{|l|l|l|l|}
\hline Duration of consciousness regaining & $\begin{array}{l}\text { Group I } \\
\text { No. 113 } \\
\mathbf{( 3 5 . 2 \% )}\end{array}$ & $\begin{array}{l}\text { Group II } \\
\text { No. 102 } \\
(\mathbf{3 1 . 7 8 \%})\end{array}$ & $\begin{array}{l}\text { Group III } \\
\text { No. 106 } \\
\mathbf{3 3 . 0 2 \%}\end{array}$ \\
\hline $\begin{array}{l}\text { 1. Ultra-short (seconds) after Yasser's Maneuver } \\
\text { 2. Short (minutes) after non-traditional methods (using painful } \\
\text { stimuli) }\end{array}$ & $5-15$ & $2-20$ & $1-6$ \\
3. Long (hours) after spontaneous recovery & & & \\
\hline
\end{tabular}

Table 3: Duration of regaining the consciousness (recovery) regard to the time in all groups

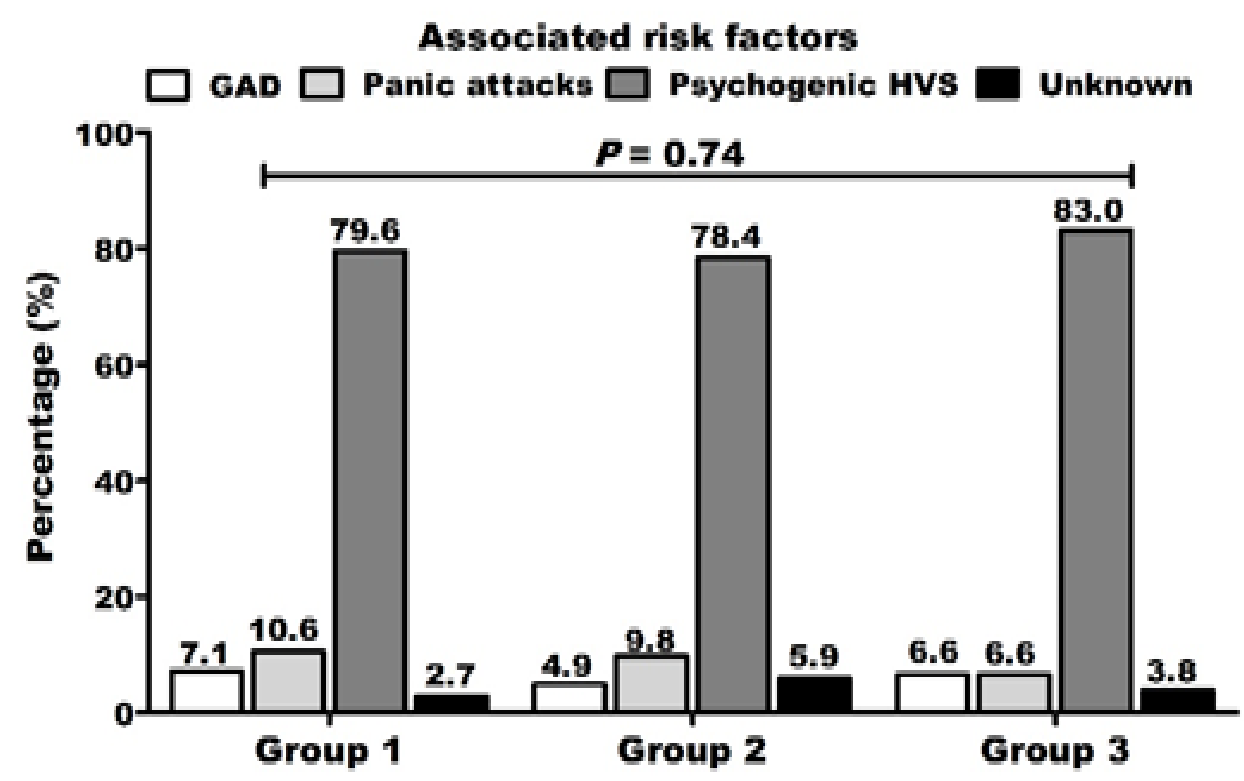

Figure 1: Graphic presentation showing the percentage of associated factors in all groups. (group I; denoted with white color, group II; denoted with gray color, and group III; denoted with black color).

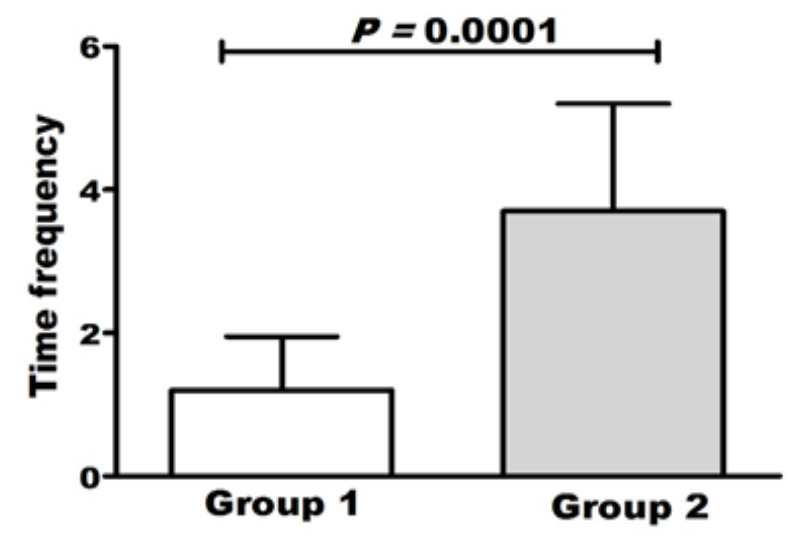

Figure 2: Graphic presentation showing times frequency in both groups I and II (group II; denoted with gray color and group III; denoted with black color). 


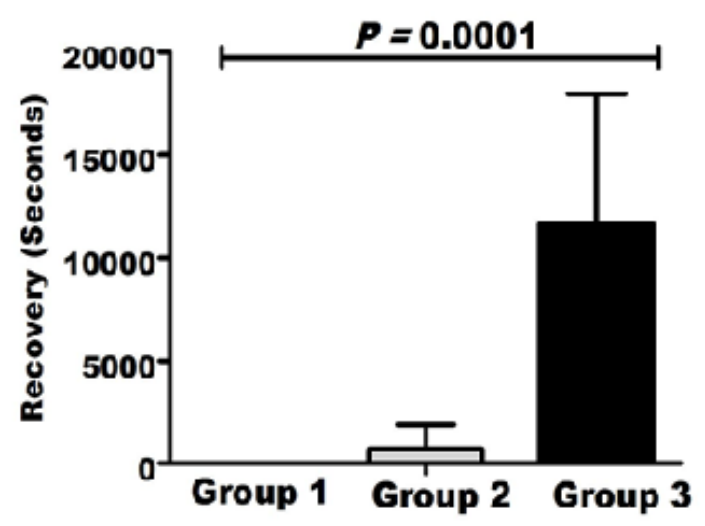

Figure 3: Graphic presentation showing the recovery in all groups (group I; denoted with white color, group II; denoted with gray color, and group III; denoted with black color).
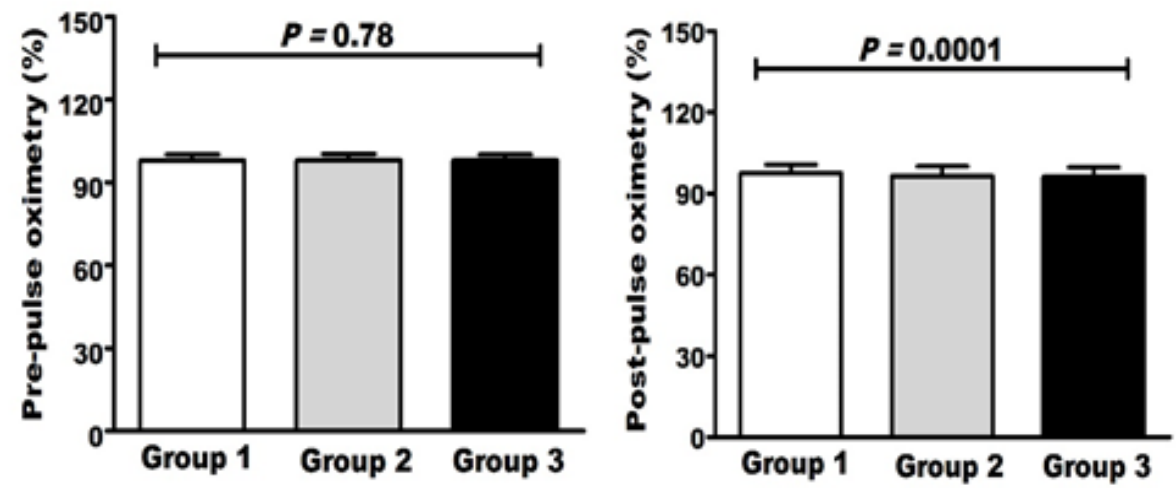

Figure 4: Left graphic presentation showing the percentage of pr-pulse oximetry in all groups. Right graphic presentation showing the percentage of post-pulse oximetry in all groups (group I; denoted with white color, group II; denoted with gray color, and group III; denoted with black color).

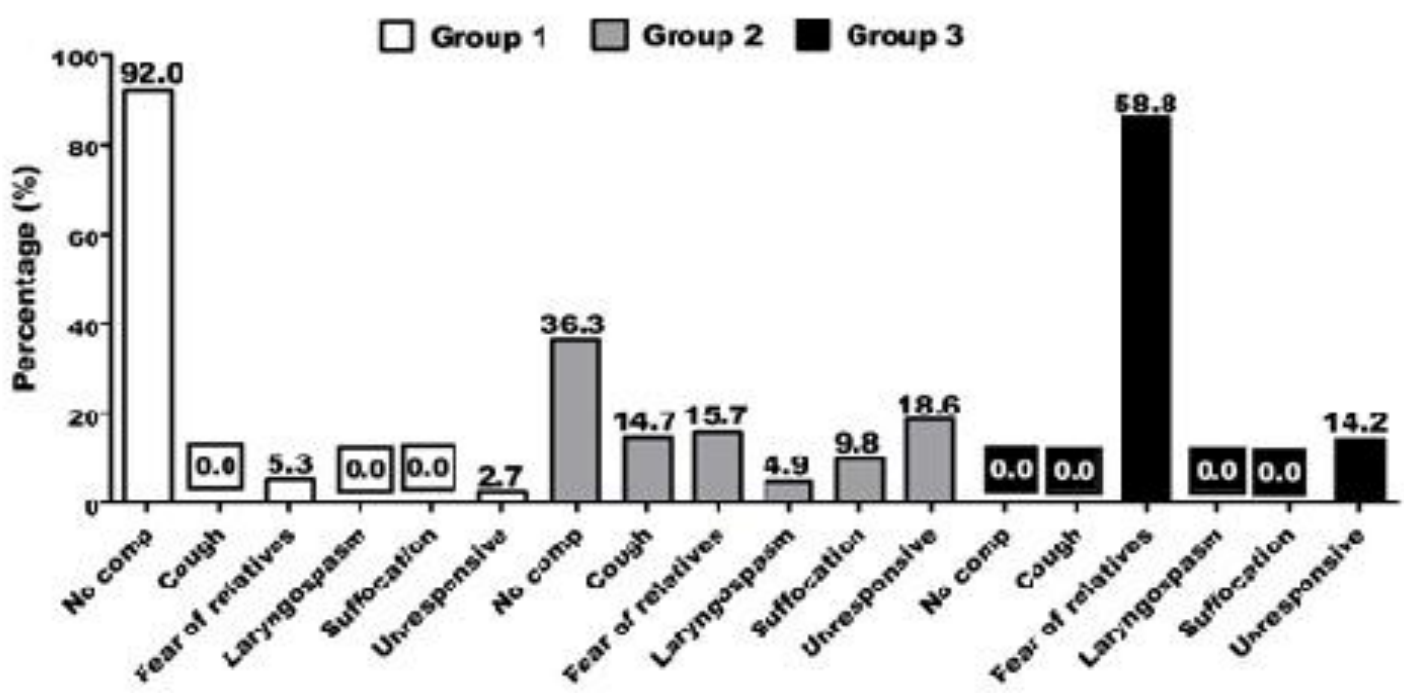

Figure 5: Graphic presentation showing the percentage of complications in all groups (group I; denoted with white color, group II; denoted with gray color, and group III; denoted with black color). 


\section{Discussion}

\section{Past studies}

Depending on the past literature publications, there were interesting case report series for psychogenic coma (1985-2018). Orr and Glassman (1985) [32] reported two cases that have been presented with a psychogenic coma secondary to hysterical conversion reactions after general anesthesia reversed by ammonia. Adams and Goroszeniuk (1991) [33] reported a hysterical case presented with a psychogenic coma following general anesthesia due to dental phobia reversed by ulnar tetany. Albrecht et al. (1995) [34] reported two cases of factitious disorder after general anesthesia; the first case was conversion disorder and reversed by cold caloric. The second case was histrionic personality traits and reversed by placebo injection. Weber et al. (1996) [35] reported a depression case presented with a psychogenic coma after use of general anesthesia for ethmoidectomy and the patient spontaneously awakened. Meyers et al. (1999) [36] reported a case of recurrent psychogenic coma following tracheal stenosis repair due to conversion disorder precipitated by unresolved psychological conflict with a long history of abuse and in each time reversed spontaneously on the removal of the endotracheal tube. Maddock et al. (1999) [14] reported an unusual hysterical depressive case postoperatively presented with psychogenic coma for nasal septum surgery reversed by occluding the patient's airway. Changa et al. (2002) [37] reported a hysterical case presented with psychogenic unconsciousness who failed to wake up promptly after total intravenous anesthesia with alfentanil and propofol. She spontaneously regained consciousness at the later 24 hours without any specific treatment. Hwang et al. (2002) [38] reported a case of dissociative amnesia presented with an acute psychiatric episode following transvaginal oocyte retrieval and reversed after three courses of supportive psychotherapy. Haller et al.
(2003) [39] reported a case of dissociative stupor as a postoperative consequence of general anesthesia or laparoscopic resection of an ovarian cyst and reversed after sublingual lorazepam. Downs JW et al. (2008) [7] reported a case presented with psychogenic coma after general anesthesia for an upper endoscopy who reversed spontaneously. Chouaib et al. (2015) [40] reported a hysterical case presented with psychogenic coma after contrasting waking electroencephalogram and responsiveness of the patient spontaneously during the implementation of a nasogastric tube. Yong et al. (2018) [41] reported a case of conversion disorder presented with psychogenic coma after dental surgery under general anesthesia who reversed spontaneously. (Table 4)

- No psychiatrist was present so who made the diagnosis of "psychogenic coma!! Indeed, there strong deficiency in psychiatrists in most relevant hospitals. This is true problem. Referral for a wherever psychiatrist sometimes was done for few unresponsive cases.

- Fear of relatives disadvantages of the study'. Indeed, fear of relatives is widely varied according to the group type or class in this study. In group I, fear of relatives was due to how to see the physician close the respiration of his or her patient, this is sometimes anxious for the relatives. In this group II, fear of relatives was weak and rapidly disappear due to rapid recovery for consciousness. In group II, fear of relatives was due to the used repeated irritating painful, or noxious stimuli. In this group II, fear of relatives was more strong and slowly disappear from relatives due to irritating used stimuli and delayed recovery for consciousness. In group III, fear of relatives was due to the very long time for recovery. Reassurance was therapy for the relatives. Indeed, the manipulation in group I and observation in group III is my work. But using irritating painful, or noxious stimuli in group II, I was just reporting the cases. This is work for my fellows in the emergency department. The author against using painful, or noxious stimuli for psychogenic coma.

\begin{tabular}{|c|c|c|c|c|c|c|}
\hline Study & Year & Sex & Primary disorder & $\begin{array}{l}\text { Secondary } \\
\text { trigger }\end{array}$ & Reversal & Reference \\
\hline 1. Orr and & 1985 & $\mathrm{~F}$ & Hysterical conversion & Operative stress & Ammonia & 32 \\
\hline Glassman & 1991 & $\mathrm{~F}$ & reactions & Dental phobia & Ulnar tetany & 33 \\
\hline 2. Adams and & 1995 & $\mathrm{~F}$ & Hysterical stupor & Operative stress & Cold calorics ${ }^{*}+$ & 34 \\
\hline Goroszeniuk & 1996 & $\mathrm{~F}$ & Conversion disorder+ & Operative stress & Placebo inj*** & 35 \\
\hline 3. Albrecht et al. & 1999 & M & factitious disorder & Operative stress & Spontaneously & 36 \\
\hline 4. Weber et al. & 1999 & $\mathrm{~F}$ & Depression & Operative stress & Spontaneously & 14 \\
\hline 5. T J Meyers et & 2002 & $\mathrm{~F}$ & Conversion disorder & Operative stress & Occluding patient's & 37 \\
\hline & 2002 & $\mathrm{~F}$ & Depression & Operative stress & airway & 38 \\
\hline 6. Maddock et al. & 2003 & $\mathrm{~F}$ & Hysterical conversion & Operative stress & Spontaneously & 39 \\
\hline 7. Changa et al. & 2008 & $\mathrm{~F}$ & reactions & Operative stress & Supportive & 1 \\
\hline 8. Hwang et al & 2015 & $\mathrm{~F}$ & Dissociative amnesia & Contrasting & psychotherapy & 40 \\
\hline 9. Haller et al & 2018 & $\mathrm{~F}$ & Dissociative stupor & waking EEG & Sublingual & 41 \\
\hline 10. Downs JW et & & & NR & Operative stress & lorazepam & \\
\hline & & & Hysterical conversion & & Spontaneously & \\
\hline 11. Chouaib et al. & & & reactions & & Spontaneously & \\
\hline 12. Yong et al. & & & Conversion disorder & & Spontaneously & \\
\hline
\end{tabular}

"; on using cold caloric, ,*; Ringer's lactate, EEG; electroencephalogram, F; Female; M; Male; NR, not reported

Table 4: Case report series for psychogenic coma from 1985 to 2018.

\section{The maneuver description}

\section{- Preparation:}

1. Take a rapid history from relatives, friends, or neighbors. Drug history, acute emotional stress, abuse of substance, psychiatric diseases, swallowing foreign body, organic diseases such as IHD, HTN, DM, etc., and poisons are mandatory.

2. Do a quick and complete physical examination. Vital signs, measuring $\mathrm{O} 2$ saturation using pulse oximetry, and random blood sugar are essential before the maneuver.

3. Do rapid exclusion for organic causes of coma.

4. Be sure that the case is a psychogenic coma. 
5. Do not allow any visitors and place the patient in a quiet observation area.

\section{- Indications:}

- Psychogenic coma

\section{- Principal:}

- Manual simultaneously and intermittently tight close both nose and mouth for seconds will be causing $\mathrm{CO} 2$ retention to the level that stimulates the brain that activating respiration and consciousness. Consequently, the brain stimulation stimulates respiration to push out the excess $\mathrm{CO} 2$.

\section{- Target:}

- The aim of this maneuver is the full regaining of consciousness.

- The maneuver and response:

- Manual simultaneously and intermittently tight close both nose and mouth for seconds.

- Nasal closure is done by tightly apply the tip of both left thumb and index to the lower nose to be assured both nostrils were closed. Simultaneously mouth closure is done by tightly apply the tip of the right index and thumb to approximate both upper and lower lip to be closed.

- Keep the nose and mouth externally closed and do not release until you experience the first desire to breathe. The first response was opening his eyes. An involuntary push of the diaphragm or swallowing movement in the throat may follow or be simultaneously associated with opening the eyes.

- Count the seconds using a watch for the time of each closure until you feel the patient open his eyes, the patient tends to breathe again or push your hands.

- During the process of the above obstruction, don't forget to give the comatose patient to open his eyes.

- Each time; the maneuver should take no more than 15 seconds.
- The number of the trial (times frequency) should not exceed more than 5 times.

\section{- Advantages:}

- The maneuver is easy, available, quick, non-costive, and extremely safe.

- The early recognition of psychogenic coma and regain consciousness can result in reduced iatrogenic complications, hospital cost, and physician anxiety.

- No need to perform an expensive workup routinely.

\section{- Disadvantages:}

- Very few non-serious complications e.g., fear of relatives $(5.31 \%)$ and unresponsiveness $(2.65 \%)$.

\section{- Contraindication:}

- Evidence of respiratory failure or central cyanosis, asthmatic or wheezy chest, a patient of known IHD or suspected ischemic chest pain, suspected acute pulmonary embolism, and suspected stroke. Do not use in a patient with a low oxygen saturation on pulse oximetry.

\section{- Post-procedure measures:}

- When the patient becomes more responsive, re-examine him, obtain a more complete history, and offer him follow-up care, including psychological support if appropriate.

- If the patient is not awake, alert, and oriented after about 15 seconds after 5 times, begin a more comprehensive medical workup and psychiatrist consultation.

- Do not ignore or release the patient who has not fully recovered. Instead, he must be fully evaluated for an underlying medical problem, which may require hospital admission.

- Reexamine the patient after regaining the consciousness.

- Do not miss the true serious medical emergencies in differential diagnoses such as pulmonary embolus, diabetic ketoacidosis, salicylate overdose, sepsis, uremia, myocardial infarction, and CVA.

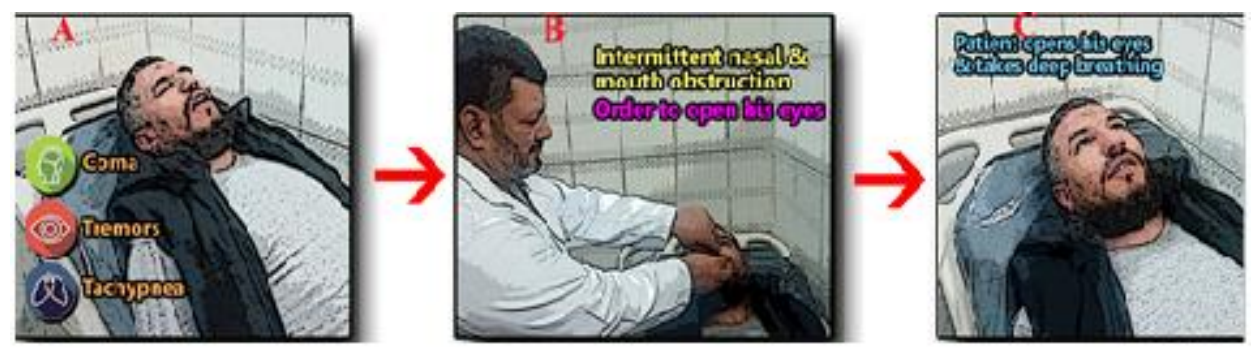

Figure 6: Drama presentation summarizes steps for Yasser's maneuver in the management of psychogenic coma. A. Step I; represent the patient presentation. B. Step II; represent the physician management using Yasser's maneuver. C. Step III; represent the patient recovery.

\section{Limitations of the study:}

Unavailable of end-tidal CO2 measurement using capnography and absence of psychiatrists at the scene of patient presentations were the main study limitations.

\section{Conclusion and recommendations}

- The author concluded that Yasser's maneuver is easy, available, quick, non-costive, time-saving, and extremely safe in the psychogenic coma. - Very few and mild few mild complications for this maneuver encourage the generalizing use in the psychogenic coma.

\section{Conflicts of interest}

There are no conflicts of interest.

\section{Acknowledgment}

- I wish to thank Prof Dr. Mohammed Omran; MD for his statistical role, Dr. Ameer Mekkawy; M.Sc. for his graphical support, nurses of the Emergency Department who helping me, and Waheed Abbas; a radiological technician for helping his drama support. 


\section{References}

1. Downs JW, MC Patrick E. Young, MC Steven J. Durning. (2008). Psychogenic Coma following Upper Endoscopy: A Case Report and Review of the Literature. Military Medicine. 173(5): 509-512.

2. Ryznar E, Wilcox D. (2019). Functional Coma: Two Case Reports and a Review of the Literature. Psychosomatics. 60(4): 343-351.

3. Ciszowski K, Mietka-Ciszowska A. (2013). Rzadkie zaburzenia świadomości w praktyce toksykologicznej: mutyzm akinetyczny, somnambulizm, zespół zamkniecia i śpiaczka psychogenna [Rare consciousness disturbances in toxicological practice: akinetic mutism, somnambulism, locked-in syndrome, and psychogenic coma]. Przegl Lek. 70(8):607-612.

4. Ludwig L, McWhirter L, Williams S, Derry C, Stone J. (2016). Functional Coma . Handb Clin Neurol. 139: 313-327.

5. Baxter CL, William WD. (2003). Psychogenic Coma: Case Report. The International Journal of Psychiatry in Medicine. 33 (3): 317-322.

6. Mann J (2002). EM guidemaps-Coma.

7. Shaibani A, Sabbagh MN. (1998). Pseudoneurologic syndromes: Recognition and diagnosis. American Family Physician. 57(10):2485-2494.

8. Yong CW, Wee Hoe Ng, Ow ATC. (2018). Psychogenic coma after dental surgery under general anaesthesia. International journal of oral and maxillofacial surgery. 47(12):1613-1615.

9. Yudofsky SC, Hales RE, editors. (2002). The APA textbook of neuropsychiatry and clinical neuroscience. Washington: American Psychiatric Association, 506.

10. Chouaib N, Chouaib H, Belyamani L, Otheman Y, Bichra MZ. (2015). Le pseudo-coma hystérique: à propos d'un cas clinique [Hysterical pseudo-coma: A case report]. Encephale. 41(4):370372.

11. Jackson AO. (2000). Faking unconsciousness. Anaesthesia. 55(4):409.

12. Posner JB (1975). Clinical evaluation of the unconscious patient. Clin Neurosurg. 22: 281-301.

13. Campbell WW. (2005). DeJong's The Neurologic Examination, $6^{\text {th }}$ Ed, pp 609-614. Philadelphia, PA, Lippincott Williams \& Wilkins.

14. Maddock H, Carley S, McCluskey A. (1999). An unusual case of hysterical postoperative coma. Anaesthesia. 54: 717-718.

15. Henry JA, Woodruff GH. (1978). A diagnostic sign in states of apparent unconsciousness. Lancet. 28; 2(8096):920-921.

16. Cartlidge N (2001). States related to or confused with coma. J Neurol Neurosurg Psychiatry. $71: 18-19$.

17. Weiss, N., Regard, L., Vidal, C. et al. (2012). Causes of coma and their evolution in the medical intensive care unit. J Neurol. 259:1474-1477.

18. Padkin A. (1999). Avoiding unnecessary trauma in the differential diagnosis of coma. Anaesthesia. 54(11):1126-1127.

19. Forster HV, Haouzi P, Dempsey JA. (2012). Control of breathing during exercise. Compr Physiol. 2:743-777.

20. Dempsey JA, Smith CA, Blain GM, Xie A, Gong Y, Teodorescu M. (2012). Role of central/peripheral chemoreceptors and their interdependence in the pathophysiology of sleep apnea. Adv Exp Med Biol. 758:343-349.

21. Kumar P, Prabhakar NR. (2012). Peripheral chemoreceptors: function and plasticity of the carotid body. Compr Physiol. 2:141219.
22. Blain GM, Smith CA, Henderson KS, Dempsey JA. (2009). Contribution of the carotid body chemoreceptors to eupneic ventilation in the intact, unanesthetized dog. J Appl Physiol. 106:1564-1573.

23. Javaheri S, Dempsey JA (2013). Central sleep apnea. Compr Physiol. 3:141-163.

24. Nurse CA (2014). Synaptic and paracrine mechanisms at carotid body arterial chemoreceptors. J Physiol. 592:3419-3426.

25. Prabhakar NR. (2013). Sensing hypoxia: physiology, genetics and epigenetics. J Physiol. 591:2245-2257.

26. Guyenet PG, Bayliss DA. (2015). Neural Control of Breathing and CO2 Homeostasis. Neuron. 87(5):946-961.

27. Gourine AV, Spyer K.M. (2003). Chemosensitivity of Medullary Respiratory Neurones A role for ionotropic P2X and GABA A receptors. CHEMORECEPTION From Cellular Signaling to Functional Plasticity. $1^{\text {st }}$ edit, pp 376. Springer Science+ Business Media New York.

28. Feng $\mathrm{Xu}$, Jinsoo Uh, Matthew R Brier, John Hart Jr, Uma $\mathrm{S}$ Yezhuvath, Hong Gu, et al. (2011). The Influence of Carbon Dioxide on Brain Activity and Metabolism in Conscious Humans. J Cereb Blood Flow Metab. 31(1):58-67.

29. Biswal B, Hudetz AG, Yetkin FZ, Haughton VM, Hyde JS. (1997). Hypercapnia reversibly suppresses low-frequency fluctuations in the human motor cortex during rest using echoplanar MRI. J Cereb Blood Flow Metab. 17(3):301-318.

30. Brian JE. (1998). Carbon Dioxide and the Cerebral Circulation. Anesthesiology 88(5):1365-1386.

31. Kinney HC, Thach BT. (2009). The sudden infant death syndrome. The New England Journal of Medicine. 361(8):795805.

32. Orr DL II, Glassman AS. (1985). Conversion phenomenon following general anesthesia. J Oral Maxillofac Surg. 43: 817819.

33. Adams AP, Goroszeniuk T. (1991). Hysteria: a cause of failure to recover after anaesthesia. Anaesthesia 46: 932-934.

34. Albrecht RF II, Wagner SR 4th, Leicht CH, Lanier WL. (1995). Factitious disorder as a cause of failure to awaken after general anesthesia. Anesthesiology 83: 201-204.

35. Weber JG, Cunnien AJ, Hinni ML, Caviness JN. (1996). Psychogenic coma after use of general anesthesia for ethmoidectomy. Mayo Clin Proc. 71: 797-800.

36. Meyers TJ, Jafek BW, Meyers AD. (1999). Recurrent psychogenic coma following tracheal stenosis repair. Arch Otolaryngol Head Neck Surg. 125(11):1267-1269.

37. Chang Y, Huang $\mathrm{CH}$, Wen YR, Chen JY, Wu GJ. (2002).Dissociative amnesia after general anesthesia-a case report. Acta Anaesthesiol Sin. 40: 101-104.

38. Hwang JL, Kuo MC, Hsieh BC, et al. (2002). An acute psychiatric episode following transvaginal oocyte retrieval. Hum Reprod. 17: 1124-1126.

39. Haller M, Kiefer K, Vogt H. (2003). Dissociative stupor as a postoperative consequence of general anesthesia. Anaesthesist. 52: 1031-1034.

40. Chouaib N, Chouaib H, Belyamani L, Otheman Y, Bichra MZ. (2015). Le pseudo-coma hystérique: à propos d'un cas clinique [Hysterical pseudo-coma: A case report]. Encephale. 41(4):370372.

41. Yong CW, Ng WH, Yap SH, D'Souza J, Ow AT. (2018). Psychogenic coma after dental surgery under general anaesthesia. Int J Oral Maxillofac Surg. 47(12):1613-1615. 